\title{
Exploring and Making Online Creative Digital Math Books for Creative Mathematical Thinking
}

\author{
Pedro Lealdino Filho, Christian Bokhove, Jean-Francois Nicaud, \\ Ulrich Kortenkamp, Mohamed El-Demerdash, Manolis Mavrikis \\ and Eirini Geraniou
}

When we look at e-books designed for mathematics education, we can distinguish two streams. On the one hand, we see publishers of traditional mathematics textbooks have digital versions of their products, mostly static pdf documents that can be downloaded and used on different devices. In anticipation of new interactive possibilities, limited interactivity is sometimes built in. On the other hand, we see innovative groups of designers that have started to develop highly interactive tools and micro-worlds for mathematics education. Initially, many of these tools were implemented as standalone applications. These tools have been increasingly integrated with written tasks, producing interactive worksheets, dynamic web pages, and e-books for math. In some European countries, the M C Squared project has aimed at starting several so-called Communities of Interest (CoI) that work on digital, interactive, and creative mathematics textbooks called c-books. The c-books are authored in the M C Squared platform, where authors can construct books using various interactive "widgets." The workshop aimed to introduce the project and acquaint participants with the affordances and authoring process of the M C Squared platform.

A short overview of M C Squared and the architecture of the authoring tool platform was given, showing the possibilities of creating c-books individually or collectively. An example of a unit of a c-book, "Experimental Geometry" (Fig. 1) was given showing the different widget factories and how they perform inside the c-book and the creative mathematical thinking affordances present in the c-book.

\footnotetext{
P.L. Filho $(\bowtie)$

Université Claude Bernard, Lyon, France

e-mail: pedrolealdino@gmail.com

(C) The Author(s) 2017

G. Kaiser (ed.), Proceedings of the 13th International Congress on Mathematical

Education, ICME-13 Monographs, DOI 10.1007/978-3-319-62597-3_123
} 


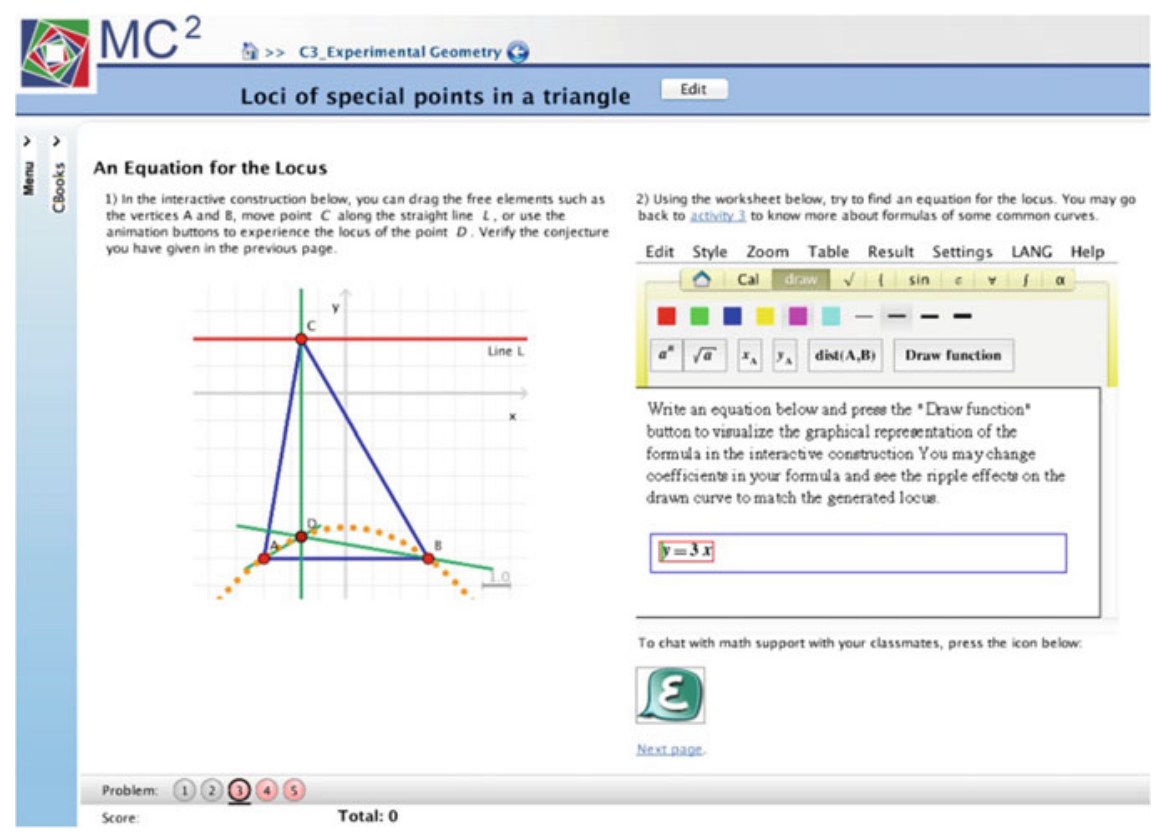

Fig. 1 Screenshot of a c-book page showing the widgets: Cinderella, EpsilonWriter and EpsilonChat

Another goal of the workshop was to teach participants how to author a simple interactive c-book and explore existing resources created along the duration of the project. The participants got acquainted with a selection of other M C Squared platform features such as student work storage and answer checking.

Open Access Except whereotherwise noted, this chapter is licensed under a Creative Commons Attribution 4.0 International License. Toview a copy of this license, visit http://creativecommons. org/licenses/by/4.0/.

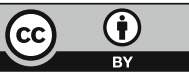

